\title{
Lithium Depletion in the Solid Electrolyte Adjacent to Cathode Materials
}

\author{
Hirotoshi Yamada ${ }^{\mathrm{a}}$, Kentaro Suzuki ${ }^{\mathrm{a}}$, Yusuke Oga ${ }^{\mathrm{b}}$, Isamu Saruwatari ${ }^{\mathrm{b}}$, Isamu \\ Moriguchi $^{\mathrm{a}}$ \\ ${ }^{\mathrm{a}}$ Graduate School of Engineering, and ${ }^{\mathrm{b}}$ Graduate School of Science and Technology, \\ Nagasaki University, Nagasaki 8528521, Japan
}

\begin{abstract}
Nanocomposites of lithium ion conductors $\left(\mathrm{Li}_{2} \mathrm{SiO}_{3}\right.$ and $\left.\mathrm{Li}_{1.3} \mathrm{Al}_{0.3} \mathrm{Ti}_{1.7}\left(\mathrm{PO}_{4}\right)_{3}\right)$ and electrode materials $\left(\mathrm{TiO}_{2}, \mathrm{Li}_{0.01} \mathrm{TiO}_{2}\right.$ and $\mathrm{FePO}_{4}$ ) were prepared to investigate interfacial structure and ionic conductivity at the interface between solid electrolytes and electrode materials. It was revealed that lithium ions in the solid electrolytes were attracted to the cathode materials with increasing electrode potential, which increases lithium vacancies in solid electrolytes. For the $\mathrm{FePO}_{4}$ containing composites, due to the high electrode potential, lithium transfer across the interface and ionic conduction through the cathode materials was remarkable. The results suggest that severe lithium depletion occurs and interfacial resistance is large at the interface of high ionic conductors and cathode materials.
\end{abstract}

\section{Introduction}

Energy storage and conversion is one of the key issues of next-generation energy systems. New energy storage systems with high energy density and high power density are strongly required, in order to enhance the efficiency of fuel consumption, to level fluctuation of electricity generated by renewable energy sources (solar power, wind power, and etc.) and to satisfy the peak energy demand with excess energy generated during off-peak time. In this context, lithium ion batteries (LIBs) and related batteries are supposed to be promising energy storage devices (1-6). Among several types of LIBs, all solid state batteries that employ solid electrolytes (especially inorganic ceramics electrolytes) attract interests because of their advantages that are hardly achieved by conventional batteries with liquid electrolytes (7-9). With solid electrolytes, reliability and safety of batteries are improved because they are nonflammable, which are very important for large-scale battery systems. With dense ceramic solid electrolytes, metallic lithium is supposed to be applied as a negative electrode, which forms dendritic lithium deposition on a charge process and causes short circuits for liquid electrolytes (10). If metallic lithium is available, the capacity of battery will be drastically increased.

The drawback of the all solid state batteries is their poor power density. This problem can be traced back to their relatively poor ionic conductivity and interfacial resistance between electrodes and solid electrolytes. On the ionic conductivity, new ionic conductors with high conductivity have been developed (11-17). For sulfides, glass ceramics in the Li-P-S system and $\mathrm{Li}_{4-x} \mathrm{Ge}_{1-x} \mathrm{P}_{x} \mathrm{~S}_{4}(x \sim 0.75)$ are reported to show the high conductivity more than $10^{-3} \mathrm{~S} \mathrm{~cm}^{-1}(13,14)$. Recently, a novel ionic conductor $\mathrm{Li}_{10} \mathrm{GeP}_{2} \mathrm{~S}_{12}$ was developed by Kanno, which shows conductivity of $10^{-2} \mathrm{~S} \mathrm{~cm}^{-1}$ (17). 
Assuming that the transference number of $\mathrm{Li}^{+}$in this solid electrolyte is unity, this material is comparable to or even surpasses liquid organic electrolytes on lithium ion conductivity. On the interfacial resistance, the other cause of the poor rate capability of the all solid state batteries, even the mechanism is still unclear, although there have been several reports on the interfacial phenomena. Ohta et al. reported that the formation of space charge layer at the interface of $\mathrm{Li}_{3.25} \mathrm{Ge}_{0.25} \mathrm{P}_{0.75} \mathrm{~S}_{4}$ that is adjacent to $\mathrm{LiCoO}_{2}$ cathode $(18,19)$. Sakuda et al. revealed formation of an interfacial phase between Li-P-S glass ceramics and $\mathrm{LiCoO}_{2}$ cathode $(20,21)$. Okumura et al. suggested an interfacial phase as well as lattice mismatch at the interface between a solid electrolyte and cathode (22). A theoretical approach using a mathematical analysis has been reported (23). But a precise model is required to investigate the actual system. Recently, several studies have been reported on interfaces between solid electrolytes and cathodes that cannot be explained by prevailing theories and phenomena, such as space charge layer model, interfacial phases, and lattice mismatch. Yamamoto et al. observed potential profiles across a battery consisting of $\mathrm{LiCoO}_{2}$ and $\mathrm{Li}_{1-x-y} \mathrm{Al}_{y} \mathrm{Ti}_{2-y} \mathrm{Si}_{x} \mathrm{P}_{3-x} \mathrm{O}_{12}$ as a cathode and a solid electrolyte, respectively (24). They found that the potential gradually decreased in the solid electrolyte for about $1 \mu \mathrm{m}$ in thickness, which is much thicker than typical thickness of the space charge layer $(\sim 10 \mathrm{~nm})$.

Generally speaking, it is difficult to study interfaces between solid electrolytes and electrodes, because of difficulty of analysis of thin layers sandwiched between two solidstate materials. Conventional spectroscopic techniques are hardly applied, because of absorption or scattering of ultraviolet, visible and infrared rays by bulk materials. Probe techniques like atomic force microscopy and scanning tunneling microscopy cannot be used either. Only a few techniques using transmission electron microscopy or X-ray absorption spectroscopy are applied to the solid-solid interface study, but obtained information is still limited.

We have investigated local structure of interfaces using nanocomposites of solid electrolytes and active materials. In the nanocomposites, interfaces dominantly affect the properties of the composites, and the interfacial phenomena can be easily detected with normal techniques $(25,26)$. In this paper, we focused the effect of active materials on solid electrolytes, and revealed that lithium ion is depleted at the interface of solid electrolytes adjacent to cathode materials (27). $\mathrm{Li}_{2} \mathrm{SiO}_{3}$ (LSO) and $\mathrm{Li}_{1.3} \mathrm{Al}_{0.3} \mathrm{Ti}_{1.7}\left(\mathrm{PO}_{4}\right)_{3}$ (LATP) were used as a solid electrolyte. The difference of these two electrolytes is their major charge carrier: lithium vacancy $\left(V_{\mathrm{Li}}{ }^{\prime}\right)$ and lithium ion $\left(\mathrm{Li}_{\mathrm{Li}}\right)$, respectively. As active materials, three materials with different electrode potentials were employed: anatase $\mathrm{TiO}_{2}$ (TO; open circuit potential (OCP) $\sim 3.3 \mathrm{~V}$ vs. $\left.\mathrm{Li} / \mathrm{Li}^{+}\right)$, lithium doped $\mathrm{TiO}_{2}\left(\mathrm{Li}_{0.01} \mathrm{TiO}_{2}\right.$ (LTO); OCP $\sim 2.7 \mathrm{~V}$ vs. $\mathrm{Li} / \mathrm{Li}^{+}$) and $\mathrm{FePO}_{4}\left(\mathrm{FPO}\right.$; OCP $\sim 3.5 \mathrm{~V}$ vs. $\mathrm{Li} / \mathrm{Li}^{+}$).

\section{Experimental}

\section{$\underline{\text { Sample Preparation }}$}

Nano LSO was prepared from commercial $\mathrm{Li}_{2} \mathrm{SiO}_{3}$ powder $(>99.5 \%$, Kishida Chemical Co. Ltd., Japan) by using a planetary ball-mill P-6 (Fritsch GmbH, Germany) at $300 \mathrm{rpm}$ for 36 hours in ethanol with a $\mathrm{ZrO}_{2}$ pot and $\mathrm{ZrO}_{2}$ balls $(3 \mathrm{~mm}$ in a diameter). After milled, the powder was dried and annealed in $\mathrm{N}_{2}$ at $200^{\circ} \mathrm{C}$ to remove adsorbed 
water and ethanol. Nano LATP was prepared from LATP powder, which was synthesized by solid state reaction using $\mathrm{Li}_{2} \mathrm{CO}_{3}, \mathrm{Al}_{2} \mathrm{O}_{3}, \mathrm{TiO}_{2}$, and $\left(\mathrm{NH}_{4}\right)_{2} \mathrm{HPO}_{4}$. These four chemicals were obtained from Kishida Chemical Co. Ltd. with a purity of $99 \%$. First, the mixture of starting materials was heated at $900^{\circ} \mathrm{C}$ for 2 hours in air. Then, the product was milled and heated again with the same condition. Finally, nano LATP was obtained by milling at $650 \mathrm{rpm}$ for $160 \mathrm{~min}$ in acetone with a $\mathrm{ZrO}_{2}$ pot and $\mathrm{ZrO}_{2}$ beads $(0.2 \mathrm{~mm}$ in a diameter). Nano $\mathrm{TiO}_{2}$ (anatase-type) was supplied as a reference catalyst JRC-TiO-1 by Catalysis Society of Japan. Nano $\mathrm{Li}_{0.01} \mathrm{TiO}_{2}$ was obtained by chemical lithium insertion to nano $\mathrm{TiO}_{2}$ by using a hexane solution of $n$-butyllithium (Wako Pure Chemical Industries, Ltd., Japan), which was diluted to $0.016 \mathrm{M}$ with hexane. Nano $\mathrm{FePO}_{4}$ was synthesized in the following three steps: first, $\mathrm{LiFePO}_{4}$ (LFP) was prepared by solid state reaction at $700^{\circ} \mathrm{C}$ for 16 hours from a mixture of $\mathrm{LiNO}_{3}, \mathrm{Fe}\left(\mathrm{NO}_{3}\right)_{3} \cdot 9 \mathrm{H}_{2} \mathrm{O}$, and $\mathrm{NH}_{4} \mathrm{H}_{2} \mathrm{PO}_{4}$ with a mole ratio of $1: 1: 1$. Then, the LFP powder was mechanically milled in ethanol by using a planetary ball-mill to obtain nano LFP particles. Finally, the nano LFP was oxidized in an acetonitrile solution of $\mathrm{NO}_{2} \mathrm{BF}_{4}(>95 \%$, Aldrich) and dried to obtain nano FPO (28). These nanoparticles of active materials were preheated in $\mathrm{N}_{2}$ at $200^{\circ} \mathrm{C}$ to remove adsorbed water, and then the nanocomposites were prepared by mechanical milling of the mixture of nanosized solid electrolytes (LSO and LATP) and nanosized active materials (TO, LTO and FPO) at $150 \mathrm{rpm}$ for 2 hours in dry Ar. OCP of all active materials was confirmed using three-electrode cells. A working electrode of a cell was a mixture of nanosized active materials, acetylene black (kindly supplied from Denki Kagaku Kogyo, Japan) and poly(tetrafluoroethylene). A reference and a counter electrode were lithium foil, and a $1 \mathrm{M}$ solution of $\mathrm{LiClO}_{4}$ in mixed solvent of propylene carbonate and 1,2-dimethoxyethane was employed as an electrolyte. All the synthesis procedure was carried out in a dry $\mathrm{N}_{2}$ or Ar atmosphere to avoid adsorption of water that may cause side reactions.

\section{$\underline{\text { Characterization }}$}

The particle sizes and dispersion of the nanoparticles and nanocomposites were analyzed by field-emission scanning electron microscopy (FE-SEM) equipped with energy dispersive X-ray (EDX) spectrometer (JSM-7500FAM; JEOL Ltd., Japan) and $\mathrm{N}_{2}$ sorption at $77 \mathrm{~K}$ (BELSORP-mini II, BEL Japan Inc., Japan). The crystal structure was investigated by X-ray diffraction (XRD) on a RINT-2200 (Rigaku Corporation, Japan).

\section{Electrochemical Analysis}

The electric conductivity of the nanoparticles and the nanocomposites were obtained by a.c. impedance spectra with a frequency range from $1 \mathrm{MHz}$ to $0.1 \mathrm{~Hz}$ with an oscillation voltage of $0.1 \mathrm{~V}$, which were conducted on a frequency response analyzer S1260 (Solartron analytical, U.K.). Specimens were uni-axially pressed into disks ( $7 \mathrm{~mm}$ in diameter and $0.5 \sim 0.7 \mathrm{~mm}$ in thickness) at $10 \mathrm{MPa}$. Gold electrodes were attached on both sides by sputtering. LSO, of which lithium ionic transference number is unity, showed a divergent straight line on Nyquist plots at a low frequency region. On the other hand, for the composites containing FPO, Nyquist plots converged on a point on the real axis, suggesting electronic conduction. To estimate the ionic conductivity, pure electronic conductivity was obtained by d.c. polarization curves with a d.c. bias of $0-2.0 \mathrm{~V}$, which were recorded on a potentio-/galvanostat S1287 (Solartron analytical, U.K.). All the 
conductivity measurements were carried out in an $\mathrm{Ar}$ atmosphere from $350^{\circ} \mathrm{C}$ to a room temperature.

\section{Results and Discussions}

\section{$\underline{\text { Nano Solid Electrolytes }}$}

Milling of commercial LSO resulted in reduction of particle size from $1 \sim 10 \mu \mathrm{m}$ to ca. $50 \mathrm{~nm}$, which was confirmed by FE-SEM. A BET specific surface area of nano LSO analyzed from the $\mathrm{N}_{2}$ sorption measurement were $21.9 \mathrm{~m}^{2} \mathrm{~g}^{-1}$ and a particle size of $54 \mathrm{~nm}$ was estimated by assuming mono-dispersed spherical particles, which agreed well with the result of the SEM observation. With increasing a milling rotation rate or a milling time, the smaller particles were obtained, while $\mathrm{ZrO}_{2}$ and $\mathrm{Li}_{2} \mathrm{CO}_{3}$ as contaminants increased. From the particle sizes and the amount of contaminants, the milling condition (300 rpm, 36 hours) was decided, which resulted in 0.11 vol.\% of $\mathrm{ZrO}_{2}$ that would be negligible in this study.

In XRD profiles of synthesized LATP, a trace of $\mathrm{AlPO}_{4}$ was confirmed, but other peaks demonstrated the formation of the NASICON-type LATP was successfully obtained. No contaminant such as $\mathrm{ZrO}_{2}$ was not observed, after the ball-milling of bulk LATP. Nano LATP was c.a. $200 \mathrm{~nm}$ in a diameter that was observed by FE-SEM.

\section{Nanocomposites of Solid Electrolytes and Active Materials}

$\underline{\mathrm{Li}}_{2} \underline{\mathrm{SiO}}_{3}-\mathrm{TiO}_{2}{ }_{2}$ Nanocomposite. For LSO-TO systems, nano TO with a diameter of $11 \mathrm{~nm}$ was used. The FE-SEM-EDX analysis showed a homogeneous dispersion of both nano LSO and nano TO in the nanocomposite of LSO-TO as shown in Fig. 1. XRD patterns indicated no structural change occurred for both nano LSO and nano TO by the mixing process. Figures 2(a) and 2(b) show the Nyquist plot of nano LSO and LSO-TO $\left(\mathrm{TiO}_{2}: 40\right.$ vol.\%), respectively, where a semi-circle and a straight line were observed for the both samples, meaning that they were not mixed conductors but ionic conductors. Figure 3 shows temperature dependent conductivity of nano LSO and composites. As clearly seen in this figure, the conductivity of LSO-TO was higher by c.a. one order of magnitude than nano LSO, and the activation energies of these two specimens were the same. This indicates the conduction mechanism in the composite is the same as that in the nano LSO, i.e., migration of Li vacancy $\left(V_{\mathrm{Li}}{ }^{\prime}\right)$. The increase in the conductivity is accounted for by the increase in the density of the charge carrier $\left(V_{\mathrm{Li}}{ }^{\prime}\right)$. All of these phenomena are well
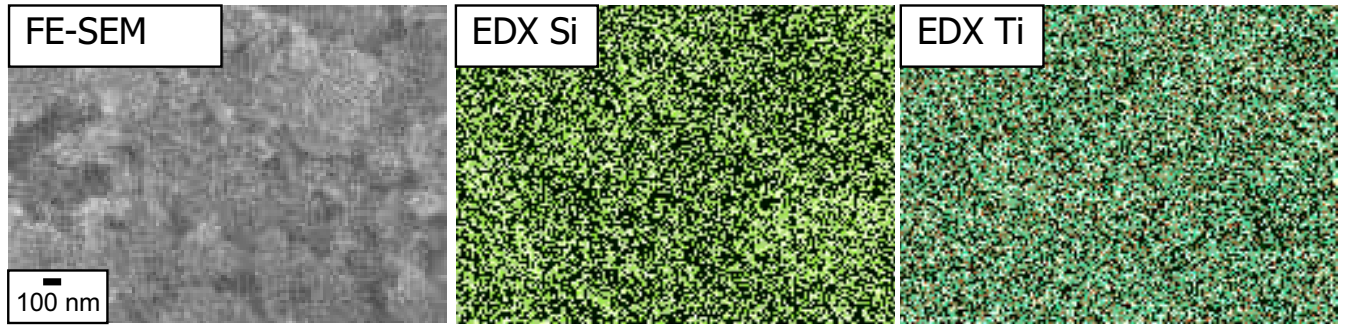

Figure 1. FE-SEM and EDX images of the nanocomposite of LSO-TO with a volume fraction of $\mathrm{TiO}_{2}$ of 0.4 . 

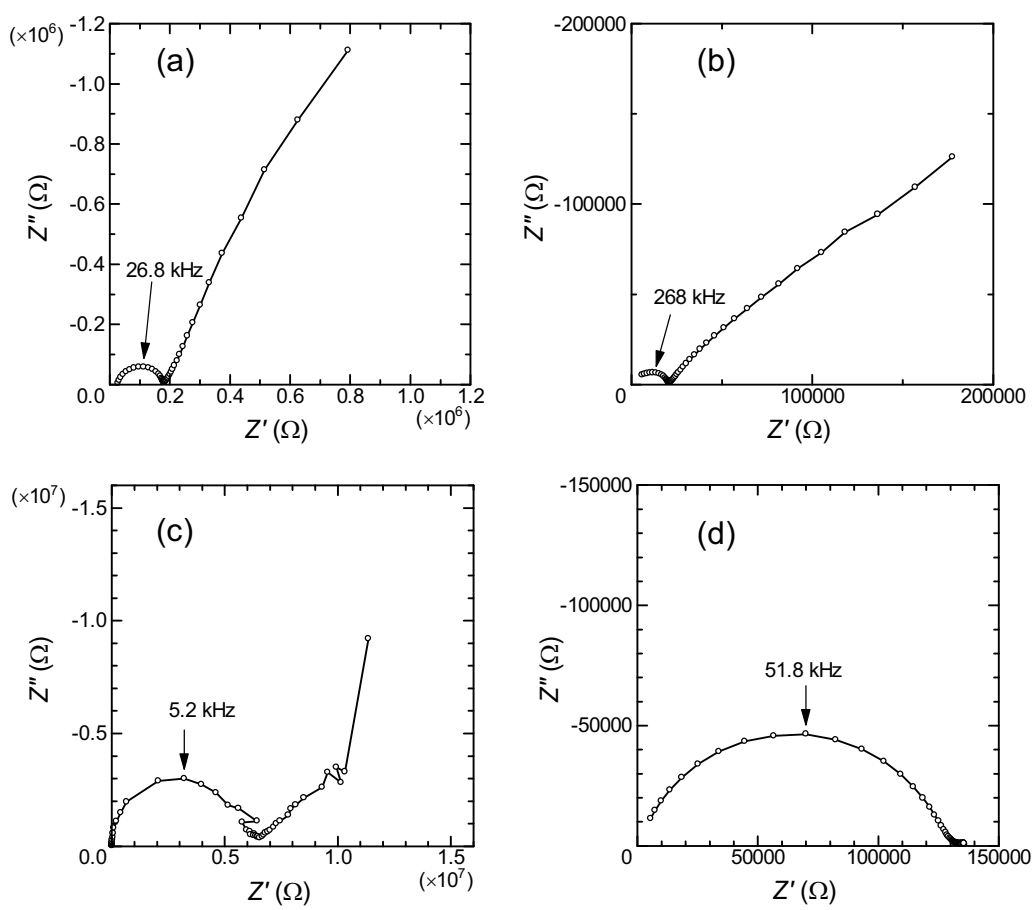

Figure 2. Nyquist plots of (a) nano LSO at $334^{\circ} \mathrm{C}$, (b) $\mathrm{LSO}-\mathrm{TO}(0.4)$ at $338{ }^{\circ} \mathrm{C}$, (c) $\mathrm{LSO}-\mathrm{LTO}(0.4)$ at $339^{\circ} \mathrm{C}$, and (d) LSO-FPO $(0.4)$ at $343{ }^{\circ} \mathrm{C}$.

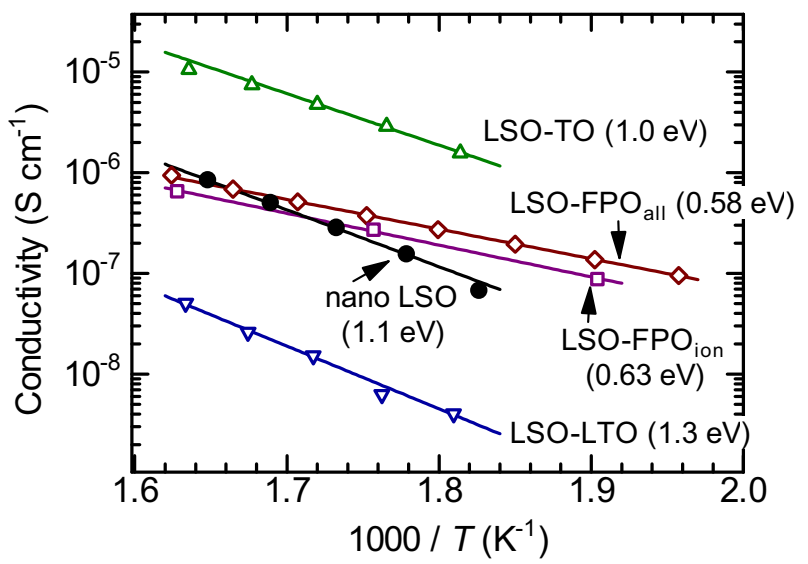

Figure 3. $\mathrm{Li}^{+}$conductivities and their activation energy of nano LSO, nanocomposites of LSO-TO, LSO-LTO and LSO-FPO with a volume fraction of active materials of 0.4.

explained by the space charge layer (SCL) model as shown in Fig. 4(b): $\mathrm{Li}^{+}$in $\mathrm{LSO}$ is attracted to the surface of $\mathrm{TiO}_{2}$ and $V_{\mathrm{Li}}{ }^{\prime}$ increases in the SCL of LSO to compensate the accumulated charge, resulting in the enhanced ionic conductivity (29). According to the SCL model with Gouy-Chapman type defects profile (30), the total conductivity of the composite $\sigma_{\mathrm{m}}$ is given by

$$
\sigma_{\mathrm{m}}=(1-\varphi) \sigma_{\infty}+\beta_{\mathrm{L}} \varphi \Omega_{\mathrm{A}} \sqrt{2 \varepsilon_{\mathrm{r}} \varepsilon_{0} R T c_{0}} u_{\mathrm{v}}
$$




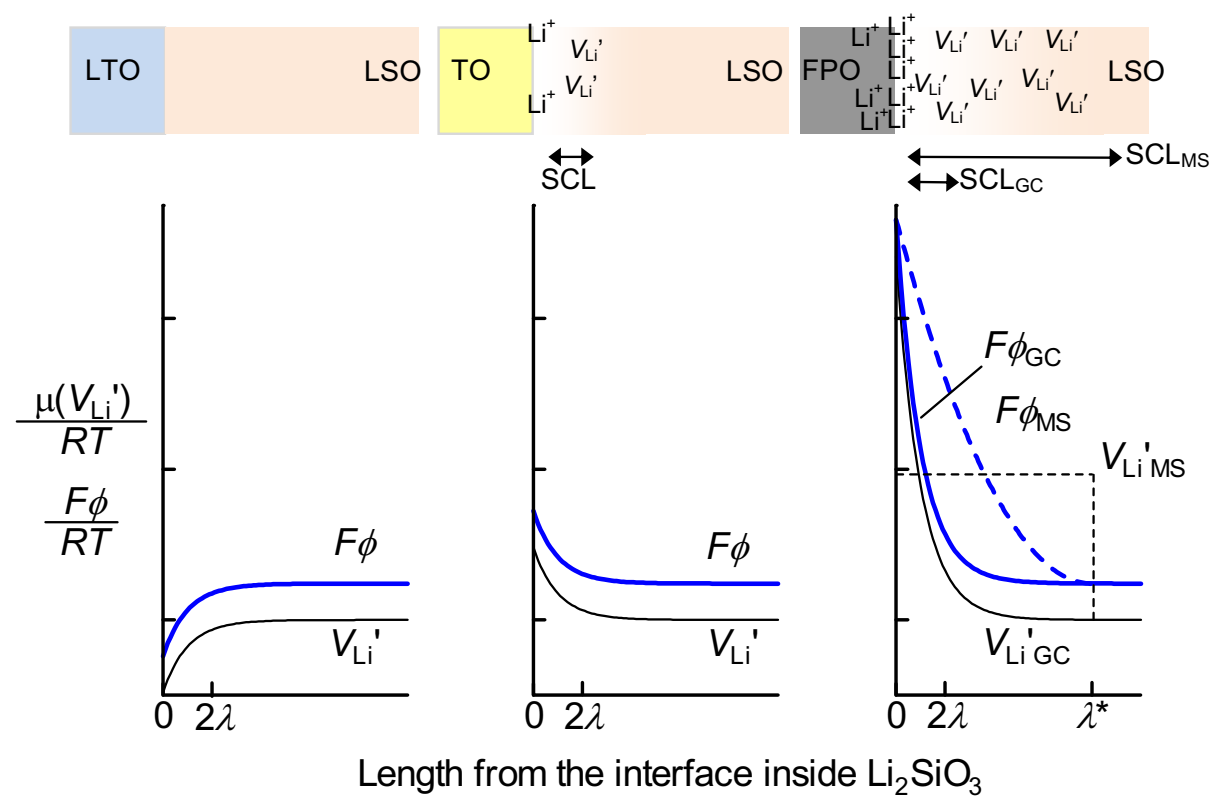

Figure 4. Schematic vacancy and potential profiles at the interfaces of LSO-side for the composites (a) LSO-LTO (OCP = 2.7 V), (b) LSO-TO (OCP = 3.3 V), and (c) LSO-FPO $(\mathrm{OCP}=3.5 \mathrm{~V})$. Solid bold line: potential $(\varphi)$, solid line: density of chemical potential of lithium vacancy $\left(\left[V_{\mathrm{Li}}{ }^{\prime}\right]\right)$. For LSO-FPO $(\mathrm{c})$, profiles for Mott-Schottky distribution are shown with dashed lines.

where $\varphi$ is the volume fraction of the second phase $\left(\mathrm{TiO}_{2}\right.$, in this case), $\sigma_{\infty}$ the conductivity in bulk; $\beta_{\mathrm{L}}$ is a factor that represents degree of percolation, $\Omega_{\mathrm{A}}$ the ratio of surface to volume of insulator phase, $\varepsilon_{\mathrm{r}}$ the relative permittivity of ionic conductor, $\varepsilon_{0}$ the permittivity of vacuum, and $u_{\mathrm{v}}$ the mobility of vacancy; $R$ is the gas constant, $T$ the temperature, and $c_{0}$ the concentration of vacancies immediately adjacent to the insulator's surface. The SCL is almost twice as thick as the Debye length $\lambda$ :

$$
\lambda=\sqrt{\frac{\varepsilon_{\mathrm{r}} \varepsilon_{0} R T}{2 z^{2} F^{2} c_{\infty}}}
$$

where $F$ is the Faraday constant and $c_{\infty}$ is the concentration of vacancies in bulk. For LSO, $\lambda$ is calculated to be about $2 \mathrm{~nm}$ at $500 \mathrm{~K}$.

Here, let us discuss the driving force of the $\mathrm{Li}^{+}$attraction by $\mathrm{TiO}_{2}$. From the thermodynamic point of view, it is supposed that $\mathrm{Li}^{+}$is more stable in or on $\mathrm{TiO}_{2}$ than in $\mathrm{Li}_{2} \mathrm{SiO}_{3}$. When two materials are in contact with each other and small amounts of $\mathrm{Li}^{+}$ transfer from material $1\left(\mathrm{Li}_{x} \mathrm{M}_{1}\right)$ to material $2\left(\mathrm{Li}_{y} \mathrm{M}_{2}\right)$, the reaction equation and the change in the Gibbs' free energy are given by

$$
\mathrm{Li}_{x} \mathrm{M}_{1}+\mathrm{Li}_{y} \mathrm{M}_{2} \rightarrow \mathrm{Li}_{x-\delta} \mathrm{M}_{1}+\mathrm{Li}_{y+\delta} \mathrm{M}_{2}
$$




$$
\Delta G=\left\{G\left(\operatorname{Li}_{x-\delta} \mathrm{M}_{1}\right)-G\left(\operatorname{Li}_{x} \mathrm{M}_{1}\right)\right\}+\left\{G\left(\mathrm{Li}_{y+\delta} \mathrm{M}_{2}\right)-G\left(\mathrm{Li}_{y} \mathrm{M}_{2}\right)\right\}
$$

It should be noted that the second term of the right hand side of Eq. [4] is proportional to the potential of the active material as written in the next equation.

$$
E\left(\mathrm{Li}_{y} \mathrm{M}_{2}\right)=-\frac{1}{F} \lim _{\delta \rightarrow 0} \frac{G\left(\mathrm{Li}_{y+\delta} \mathrm{M}_{2}\right)-G\left(\mathrm{Li}_{y} \mathrm{M}_{2}\right)}{\delta}
$$

Therefore, with decreasing the electrode potential $(E(y)$ in Eq. [5]), $\Delta G$ increases, meaning the equilibrium of Eq. [3] shifts toward left and vacancy in the material 1 $\left(\mathrm{Li}_{x} \mathrm{M}_{1}\right)$ decreases. On the other hand, when $E(y)$ is increased, $\Delta G$ decreases and vacancy in the material 1 increases.

$\underline{\mathrm{Li}}_{2} \underline{\mathrm{SiO}}_{3}-\underline{\mathrm{Li}}_{0.01} \underline{\mathrm{TiO}}_{2}$ Nanocomposite. According to the above model, $\mathrm{Li}^{+}$doped $\mathrm{TiO}_{2}$ $\left(\mathrm{Li}_{y} \mathrm{TiO}_{2}\right.$, LTO), which shows lower electrode potential than $\mathrm{TiO}_{2}$ is supposed to show weaker attraction (or $\mathrm{Li}^{+}$donation) In this study, nano LTO with $y=0.01$ and $E(y)=2.7$ $\mathrm{V}$ vs. $\mathrm{Li} / \mathrm{Li}^{+}$was prepared and mixed with nano $\mathrm{LSO}$ with a volume fraction of nano LTO of 0.4. For LSO-LTO, it is expected that less $\mathrm{Li}^{+}$would be attracted to the interface due to the lower electrode potential, according to Eq. [5]. In the Nyquist plot of LSO-LTO (Fig. 2(c)), a semi-circle and a straight line appeared, indicating the electronic conduction was negligible. Figure 3 shows that the conductivity of LSO-LTO decreased to 1/20 of that of the pristine nano LSO with almost the same activation energy. In addition, crystal structure of nano LSO and nano LTO in the composite was the same as those of the pristine ones. This result is well explained by the above model. That is, the conductivity decreases because LTO behaves as just inert phase in the composite or LTO may behave as $\mathrm{Li}^{+}$donor to LSO, which decreases $V_{\mathrm{Li}}{ }^{\prime}$ in LSO and decreases $\sigma_{\mathrm{Li}}$ of LSO (Fig. 4(a)).

$\underline{\mathrm{Li}}_{2} \underline{\mathrm{SiO}}_{3}-\mathrm{FePO}_{4}$ Nanocomposite. To study composites with higher electrode potential, $\mathrm{FePO}_{4}(\mathrm{FPO})$ with a potential of $3.5 \mathrm{~V}$ vs. $\mathrm{Li} / \mathrm{Li}^{+}$was used as an active material. For LSO-FPO, according to Eq. [5], it is expected that more Li ions are attracted to the interface due to the higher electrode potential. For the composite of LSO-FPO, Fig. 2(d) indicated that the Nyquist plot converged at a point on the real axis for lower frequency limit, meaning electronic conduction in the composite was not negligible. Therefore, $\sigma_{\mathrm{e}}$ of
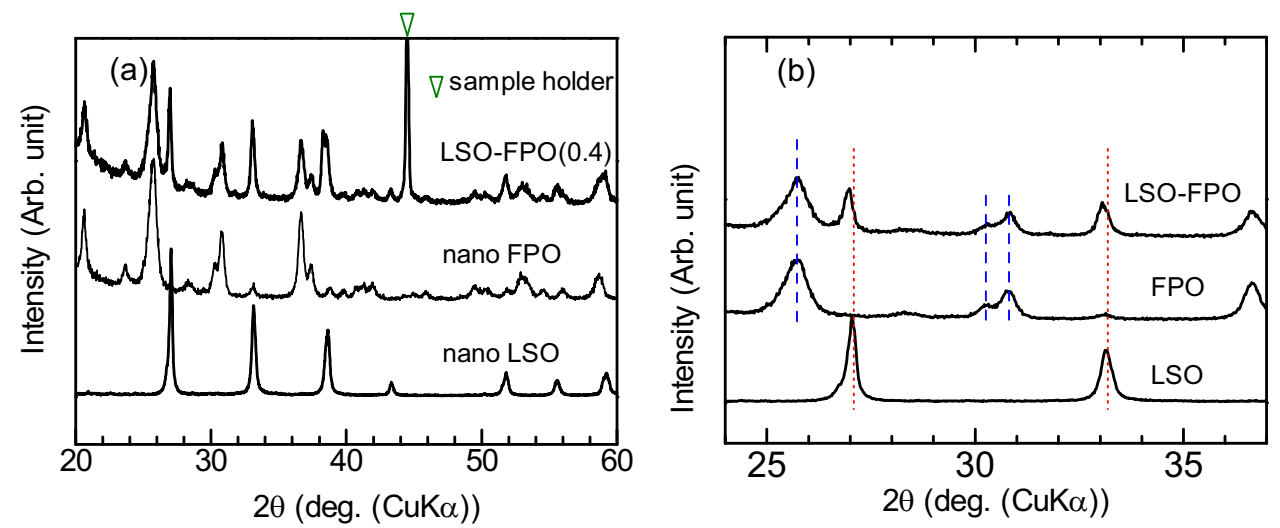

Figure 5. (a) XRD profiles of nano LSO and LSO-FPO $(\varphi=0.4)$ and (b) their enlarged profiles. 
LSO-FPO was obtained from d.c. polarization. $\sigma_{\mathrm{e}}$ was estimated from the slope by using Ohm's law. $\sigma_{\mathrm{Li}+}$, which was estimated from ac impedance and dc polarization, was slightly increased at lower temperatures in comparison to nano LSO (Fig. 3). It should be noted that the particle size of nano FPO was about $800 \mathrm{~nm}$ and much larger than nano TO and nano LTO $(11 \mathrm{~nm})$, and it is impossible to compare LSO-FPO with other composites. Interestingly, the activation energy of LSO-FPO composite was smaller than that of the pristine nano LSO. This indicates the change in the ionic conduction mechanism and/or the change in the structure of LSO. XRD measurement didn't show the existence of any impurity phases for the LSO-FPO composite as shown in Fig. 5(a). However, diffraction peaks related to LSO in the composite appeared at lower angles compared to pristine nano LSO, while those of nano FPO didn't shift (Fig. 5(b)). This result indicates that the lattice expansion occurred for nano LSO in the composite. The calculated lattice parameters of LSO in the composite was larger than that of the pristine nano LSO $(+1.3 \%$ in cell volume), but standard deviations of those values for the composite were large and it was difficult to distinctly demonstrate the lattice expansion.

For the $\mathrm{Li}^{+}$conduction in LSO-FPO, two plausible mechanisms are proposed (Fig. 4(c)). The first model is that lithium ions in LSO are strongly attracted on the surface of FPO because the energy gain of Li transfer to FPO ( $\Delta G$ in Eq. [5]) is large. This causes many lithium ion vacancies $\left(V_{\mathrm{Li}}{ }^{\prime}\right)$ in the LSO. While a lot of $V_{\mathrm{Li}}{ }^{\prime}$ enhance the ionic conductivity as explained by the space charge layer model, they also cause the lattice expansion, because $V_{\mathrm{Li}}{ }^{\prime}$ have negative relative charge in the crystal and they repulse each other. The expanded lattice results in wider bottle-neck on the $\mathrm{Li}^{+}$conduction and reduces the potential barrier on the $V_{\mathrm{Li}}{ }^{\prime}$ (or $\mathrm{Li}^{+}$) migration. The other plausible mechanism would be the $\mathrm{Li}^{+}$conduction in FPO. That is, a few lithium ions were inserted from LSO into FPO on their contact interfaces and conduct charges in FPO. This is supported by the fact that the observed activation energy of $0.63 \mathrm{eV}$ is close to that for $\mathrm{LiFePO}_{4}, 0.55-0.59 \mathrm{eV}$ (31). This local reaction between LSO and FPO is not surprising, although LSO is electrochemically stable at this potential of $3.5 \mathrm{~V}$ vs. $\mathrm{Li} / \mathrm{Li}^{+}$. This kind of lithium insertion from electrolytes to active materials is confirmed by simulation. At an interface of $\mathrm{V}_{2} \mathrm{O}_{5}$ and $\mathrm{Li}_{2} \mathrm{SiO}_{3}$ glass, small amounts of $\mathrm{Li}^{+}$were inserted into $\mathrm{V}_{2} \mathrm{O}_{5}$ without the presence of an electric field (32).

We shall discuss defects profiles at the interfaces in detail. For the SCL model, two defects profiles are proposed: Gouy-Chapman (GC) profile and Mott-Schottky (MS) profile. ${ }^{29}$ For the GC case, defects are distributed on the basis of the Poisson-Boltzmann distribution in which electrochemical potential of all species is constant, and the SCL thickness $(\sim 2 \lambda)$ is independent of surface potential as mentioned earlier. On the other hand, for the MS profile, the charge concentration is supposed to be constant in the SCL. In this case, the SCL thickness $\left(\lambda^{*}\right)$ depends on the surface potential as follows:

$$
\lambda^{*}=\sqrt{\frac{2 \varepsilon_{\mathrm{r}} \varepsilon_{0}}{z F c_{\infty}}\left(\phi_{\infty}-\phi_{0}\right)}
$$

where $\phi_{\infty}$ and $\phi_{0}$ are potential in bulk and at the interface, respectively. Equation [6] indicates that the MS-type SCL can be thicker than the GC-type SCL. For LSO-FPO, the MS model may be applied due to the high surface potential (see dashed line in Fig. 4(c)). If such high surface potential is applied to GC distribution, the calculated defects 
concentration is higher than the concentration of all $\mathrm{Li}$ ions at the surface of LSO. In addition, the increase in the defects decreases the lattice energy, which suppresses formation of defects. Therefore, the concentration of defects is supposed to be saturated at a certain value and the MS type distribution is applied. The very thick depletion region $(\sim 1 \mu \mathrm{m})$ at the interface observed by electron holography may be also explained with the MS-like model. ${ }^{24}$

$\underline{\mathrm{Li}}_{1.3} \underline{\mathrm{Al}}_{0.3} \underline{\mathrm{Ti}}_{1.7}\left(\mathrm{PO}_{4}\right)_{3}-\underline{F e P O}_{4}$ Nanocomposite. LSO is not a common solid electrolyte, because of their poor ionic conductivity $\left(\sim 10^{-7} \mathrm{~S} \mathrm{~cm}^{-1}\right.$ at room temperature). This is partially because all of $\mathrm{Li}^{+}$sites in $\mathrm{LSO}$ are occupied by $\mathrm{Li}^{+}$. In $\mathrm{LSO}$, major charge carrier is lithium-ion vacancies $\left(V_{\mathrm{Li}}{ }^{\prime}\right)$ that are thermally generated together with interstitial lithium ions $\left(\mathrm{Li}_{\mathrm{i}}{ }^{\circ}\right)$. As discussed above, an adjacent cathode would increase $V_{\mathrm{Li}}{ }^{\prime}$, resulting in the increase of the ionic conductivity. On the other hand, in typical ionic conductors, site occupancy of $\mathrm{Li}^{+}$is not unity and their major charge carrier is lithium ions itself $\left(\mathrm{Li}_{\mathrm{Li}}\right)$. According to the above suggested mechanism, contact with high-potential cathode materials would result in carrier depletion in solid electrolyte at the interface. To confirm this, nano LATP was mixed with nano FPO and structure of the nanocomposite was investigated.
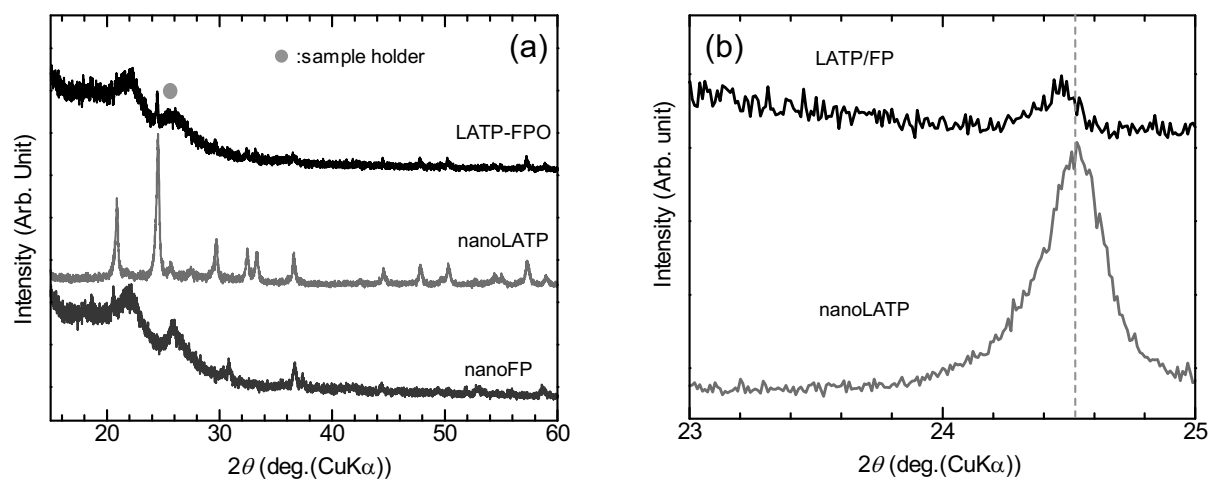

Figure 6. (a) XRD profiles of nano LATP and LATP-FPO $(\varphi=0.4)$ and (b) their enlarged profiles.

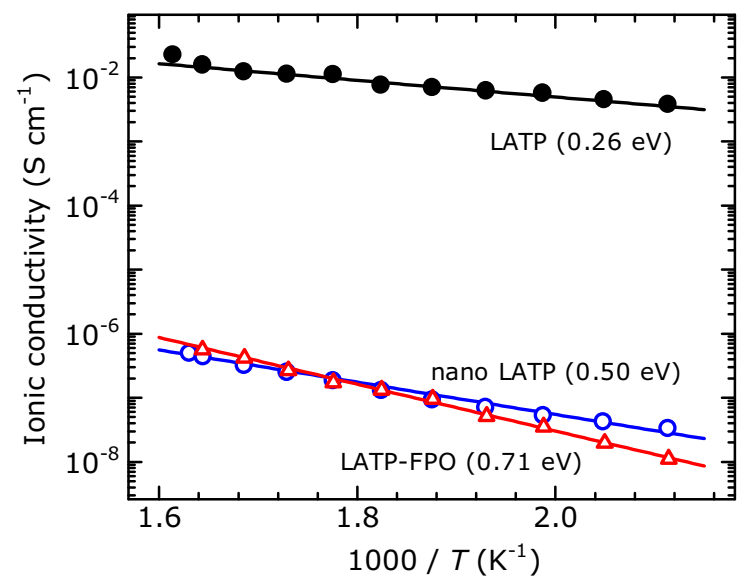

Figure 7. $\mathrm{Li}^{+}$conductivities and activation energies of $\mathrm{Li}^{+}$conduction of LATP, nano LATP and nanocomposite of LATP-FPO with a volume fraction of active materials of 0.4 . 


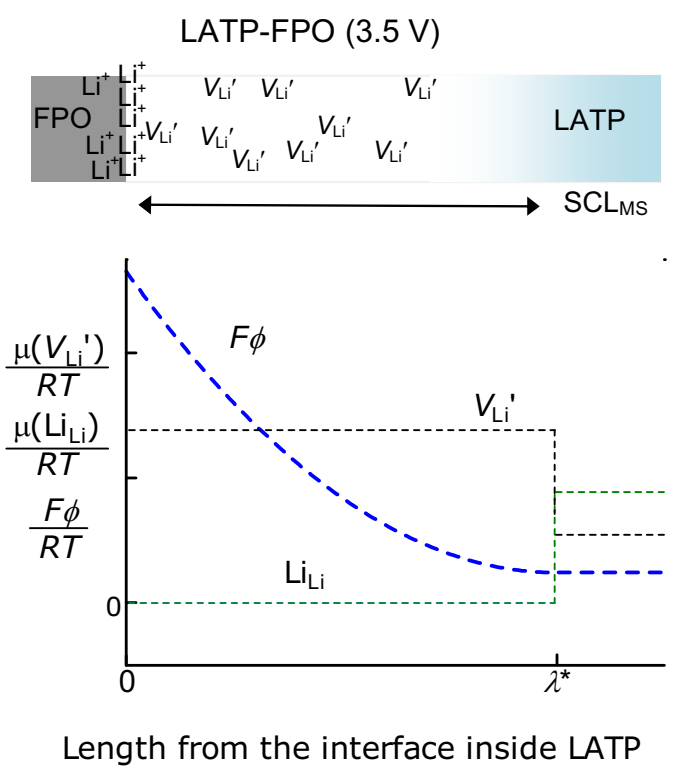

Figure 8. Schematic vacancy and potential profiles at the interfaces of LATP-side for the composite LATP-FPO $(\mathrm{OCP}=3.5 \mathrm{~V})$. Blue dashed bold line: potential $(\phi)$, dashed black line: chemical potential of lithium vacancy $\left(\left[V_{\mathrm{Li}}{ }^{\prime}\right]\right)$ and dashed green line: chemical potential of lithium ion $\left(\left[\mathrm{Li}_{\mathrm{Li}}\right]\right)$. Defect profiles are drawn assuming Mott-Schottkey distribution.

Figure 6 shows XRD patterns of bulk LATP, nano LATP and LATP-FPO. The diffraction peaks of LATP in the composite shifted toward lower angle, which is similar to LSO in nano LSO-FPO. This indicates lithium transfer from LATP to the FPO across interfaces. The ionic conductivity of these materials is shown in Fig. 7. It should be noted that nano LATP showed lower conductivity than bulk LATP. This is partially because increase of grain boundary resistance. In addition, it is supposed that the milling process caused lithium extraction from the LATP surface, which decreased charge carrier at the surface. The lithium extraction due to a milling process was also observed for nano LSO. For the nanocomposite LATP-FPO, the ionic conductivity was lower than nano LATP, which demonstrates the above proposed model. In the case of LATP, Li ion $\left(\mathrm{Li}_{\mathrm{Li}}\right)$ is the major charge carrier, and the extraction of $\mathrm{Li}^{+}$means depletion of the charge carrier, which decreases ionic conductivity (Fig. 8). The addition of FPO caused the increase in the activation energy of the ionic conduction from $0.50 \mathrm{eV}$ to $0.71 \mathrm{eV}$ in spite of the lattice expansion of LATP, which is the opposite trend in comparison with LSO-FPO. Therefore, the lattice expansion model is less possible. What is more, the activation energy of $0.71 \mathrm{eV}$ is higher than $0.55-0.59 \mathrm{eV}$ for $\mathrm{LiFePO}_{4}$, and the lithium conduction through FPO may not be appropriate, either. To investigate ionic conduction mechanism for composites of LSO-FPO and LATP-FPO, further detailed study is needed.

\section{Conclusion}

At interfaces of solid electrolytes and active materials, lithium-ion transfer across the interfaces occurs, which depends on the potential of the active materials. The $\mathrm{Li}^{+}$transfer 
causes change in the ionic conductivity at the interface and, in some cases, changes in the lattice expansion.

\section{Acknowledgements}

This work was financially supported by Grant-in-Aid for Scientific Research on Priority Areas "New Frontier of Hetero-Interface Modification for High Temperature Applications Based on Nanoionics Principles" (439), the Ministry of Education, Culture, Sports, Science \& Technology (MEXT), Japan, as well as by Tokuyama Science Foundation.

\section{References}

1. P. G. Bruce, Chem. Comm., 19, 1817 (1997).

2. C. Fellner and J. Newman, J. Power Sources, 85, 229 (2000).

3. I. Moriguchi, R. Hidaka, H. Yamada, T. Kudo, H. Murakami and N. Nakashima, Adv. Mater. , 18, 69 (2006).

4. H. Yamada, K. Tagawa, M. Komatsu, I. Moriguchi and T. Kudo, J. Phys. Chem. $C, \mathbf{1 1 1}, 8397$ (2007).

5. P. G. Bruce, B Scrosati and J.-M. Tarascon, Angew. Chem. Int. Ed., 47, 2930 (2008).

6. H. Yamada, Y. Watanabe, I. Moriguchi and T. Kudo, Solid State Ionics, 179, $1706(2008)$.

7. K. M. Abraham, Electrochim. Acta, 38, 1233 (1993).

8. K. Takada, T. Inada, A. Kajiyama, M. Kouguchi, H. Sasaki, S. Kondo, Y. Michiue, S. Nakano, M. Tabuchi and M. Watanabe, Solid State Ionics, 172, 25 (2004).

9. J. B. Bates, N. J. Dudney, B. Neudecker, A. Ueda and C. D. Evans, Solid State Ionics, 135, 33 (2000).

10. D. Aurbach, A. Zaban, A. Schechter, Y. Ein-Eli, E. Zinigrad and B. Markovsky, J. Electrochem. Soc., 142, 2873 (1995).

11. H. Aono, E. Sugimoto, Y. Sadaoka, N. Imanaka and G. Adachi, Chem. Lett., 19, 331 (1990).

12. Y. Inaguma, C. Liquan, M. Itoh, T. Makamura, T. Uchida, H. Ikuta and M. Wakihara, Solid State Comm., 86, 689 (1993).

13. R. Kanno, M. Murayama, J. Electrochem. Soc., 148, A742 (2001).

14. M. Tatsumisago and A. Hayashi, in Solid State Ionics for Batteries, T. Minami, M. Tatsumisago, C. Iwakura, S. Kohjiya and I. Tanaka, Editor, Ch. 3.2, Springer, Tokyo, (2005).

15. R. Murugan, V. Thangadurai and W. Weppner, Angew. Chem. Int. Ed., 46, 7778, (2007.)

16. P. Knauth, Solid State Ionics, 180, 911 (2009).

17. N. Kamaya, K. Homma, Y. Yamakawa, M. Hirayama, R. Kanno, M. Yonemura, T. Kamiyama, Y. Kato, S. Hama, K. Kawamoto, and A. Mitsui, Nature Mater., 10, $682(2011)$.

18. N. Ohta, K. Takada, L. Zhang, R. Ma, M. Osada and T. Sasaki, Adv. Mater., 18, 2226 (2006). 
19. N. Ohta, K. Takada, I. Sakaguchi, L. Zhang, R. Ma, K. Fukuda, M. Osada and T. Sasaki, Electrochem. Commun., 9, 1486 (2007).

20. A. Sakuda, H. Kitaura, A. Hayashi, K. Tadanaga and M. Tatsumisago, Electrochem. Solid-State Lett., 11, A1 (2007).

21. A. Sakuda, A. Hayashi and M. Tatsumisago, Chem. Mater., 22, 949 (2010).

22. T. Okumura, T. Nakatsutsumi, T. Ina, Y. Orikasa, H. Arai, T. Fukutsuka, Y. Iriyama, T. Uruga, H. Tanida, Y. Uchimoto and Z. Ogumi, J. Mater. Chem., 21, 10051 (2011).

23. M. Landstorfer, S. Funken and T. Jacob, Phys. Chem. Chem. Phys., 13, 12817 (2011).

24. K. Yamamoto, Y. Iriyama, T. Asaka, T. Hirayama, H. Fujita, C. A. J. Fisher, K. Nonaka, Y. Sugita and Z. Ogumi, Angew. Chem. Int. Ed., 49, 4414 (2010).

25. H. Yamada, I. Moriguchi and T. Kudo, Solid State Ionics, 176, 945 (2005).

26. H. Yamada, A. J. Bhattacharyya and J. Maier, Adv. Funct. Mater., 16, 525 (2006).

27. H. Yamada, Y. Oga, I. Saruwatari and I. Moriguchi, J. Electrochem. Soc., 159(4), A380 (2012).

28. A. Yamada, H. Koizumi, N. Sonoyama and R. Kanno, Electrochem. Solid-State Lett., 8, A409 (2005).

29. J. Maier, J. Phys. Chem. Solids, 46, 309 (1985).

30. X. Guo, I. Matei, J. Jamnik, J.-S. Lee and J. Maier, Phys. Rev. B, 76, 125429 , (2007).

31. R. Amin, P. Balaya and J. Maier, Electrochem. Solid-State Lett., 10, A13 (2007).

32. M. E. Garcia, E. Webb III and S. H. Garofalini, J. Electrochem. Soc., 145, 2155 (1998). 